\title{
A Different Take on the Deliberative Poll: Information, D eliberation and Attitude Constraint
}

\author{
Patrick Sturgis, U niversity of Surrey, U K
}

Caroline Roberts, London School of Economics and Political Science

Nick A llum, London School of Economics and Political Science

Paper Presented at the 58th International Conference of the American Association of Public Opinion Research (AAPOR), N ashville, USA, August 15-18, 2003.

\begin{abstract}
Opinion pollsters, political scientists and democratic theorists have long been concerned with the normative and methodological implications of nonattitudes (Converse, 1964). Of the proposed remedies to the weak and labile attitudinal responses proffered by an uninformed and disinterested public, perhaps the most ambitious to date has been Fishkin's concept of the deliberative poll (Fishkin, 1991; 1995; 1997). Combining probability sampling with information intervention and increased deliberation affords a unique insight into what might be considered the true 'voice of the people'. Yet while deliberative polling draws heavily on the general notion of political sophistication (Luskin, 1987), empirical analyses have tended to focus almost entirely on how the process of deliberation impacts on marginal totals of attitude items at both the individual and aggregate level (Fishkin, 1997; Luskin, Fishkin and Jowell, 2002; Sturgis 2003). Little attention, in contrast, has been paid to outcomes that relate to other dimensions of opinion quality, such as attitude constraint. Constraint refers to the level of consistency between attitudes within an individual belief system which arises from a combination of logical, social and psychological factors (Converse 1964). In this paper we analyse data from five deliberative polls conducted in the UK in the 1990s to investigate the impact of political information and deliberation on attitude constraint. Across a broad range of issue areas we evaluate the extent to which the deliberative process impacts on statistical associations amongst attitude items between the first and subsequent waves of the polls. We conclude by discussing the implications of our results for the validity and reliability of survey measures of the attitude and the broader utility of the del iberative polling method as a tool of social scientific enquiry.
\end{abstract}

Key words: political sophistication; opinion quality; attitude constraint; deliberative poll.

\section{POLITICAL SOPHISTICATION AND 'INFORMED’ OPINION}

If political science as a discipline can claim to have uncovered any scientific 'facts' during its relatively brief existence, then the politically unsophisticated electorate is undoubtedly a primary contender. In survey after survey the inability of the public to accurately identify the institutional structures of government, office holders and important areas of elite controversy has been repeatedly demonstrated 
through decades of empirical research (Hyman and Sheatsley 1947; Campbell et al 1960; Bennett 1988, Delli Carpini and Keeter 1996). Comparative time series of survey data confirm the initial conclusions of the Michigan School, that respondents willingly offer opinions on nonexistent issues (Bennett 1975; Bishop et al 1980); misunderstand and misrepresent abstract, ideological terminology (Campbell et al 1960; Converse 1964; Butler and Stokes 1969; Erikson and Luttbeg 1973); switch from one side to the other of prominent issues in a quasi-random manner over time (Converse ibid; lyengar 1973; Asher 1974; Sturgis 2002); and demonstrate only weak consistency between issues which elites routinely parcel together (Converse ibid; Butler and Stokes 1974; Converse and Pierce 1985). This body of empirical work has given rise to concerns over the ability of the public to meet the exigencies of normative theories of democracy and the validity and reliability of survey attitude data more generally.

If the responses proffered in the standard survey interview are not, then, to be trusted how can we come to know public opinion? The list of proposed methodological remedies to this question is long and growing. Some of the more straightforward approaches involve only slight modifications to the standard questionnaire format. It is now common practise, for instance, to provide 'preambles' for questions on low salience topics in order to provide respondents with at least some limited frame of reference within which to formulate a response; "you may have heard of issue $X$, this is...". Similarly, although not always recognised as such, the inclusion of 'don't know' and' can't say' response alternatives, is an implicit recognition that not all respondents will have a stance on every issue. Opinion filtering, a la Schuman and Presser (1981), is a yet more robust attempt at weeding out the nonattitude holders to providea 'purified' measure of the public will.

Where such 'filtering' approaches fall down, of course, is in assuming - if only implicitly - that the distribution of 'true' issue preferences is itself uncorrelated with opinion holding (Delli Carpini and Keeter 1996). For the same reason, the notion of 'rationality through aggregation' (Page and Shapiro 1992) has been critiqued for assuming that "the actual signal of net change can come equiprobably from any stratum of the electorate" (Converse 2000 p.349). On the contrary, however, the evidence that the aggregate distribution of opinion on many issues would be different, were people better informed, is compelling (Bartels 1996; Althaus 1998; Sturgis 2001; Sturgis 2003). The key problematic is not, then, how to identify and remove the nonattitude holders but to estimate what the public as a whole would think were they better informed about the issues in question.

Clearly, this is a far from straightforward task - the gulf that separates the least sophisticated members of the public from their 'elite' counterparts is so vast that it would, in all reality, take years of dedicated study to even come close to broaching it (see Converse 2000 p.333-335 for a vivid discussion of this point). Many attempts at solving the problem of estimating 'informed opinion' founder on the 
problem of response burden that this throws up. In delivering levels of information deemed sufficient for eliciting enlightened preferences, most have had to give up on random selection of samples and, thereby, representativeness. Under this general umbrella would fall techniques such as focus group discussions (Kreuger 1988), Citizens' Juries (Coote and Lenaghan 1997; Wakeford 2003), Planning Cells (Renn et al 1984) and other methods based on 'opt-in' sample designs. Other approaches have retained a probability based sample design but implemented only relatively modest 'interventions' (Neijens 1987; van Knippenberg and Daamen 1996); or relied on statistical modeling of cross-sectional data in preference over quasi-experimental designs (Bartels 1996; Delli Carpini and Keeter 1996; Althaus 1998; Gilens 2002; Sturgis 2001; 2003). We do not discuss such approaches further here but restrict our attention to a consideration of the most ambitious approach to date of estimating informed opinion, while retaining the possibility of inference to the population through random selection of samples - Fishkin's Deliberative Poll (Fishkin 1991; 1995; 1997; Luskin, Fishkin and Jowell 2002).

The basic design of a deliberative poll involves interviewing a randomly selected sample of the population on their views on a particular issue or range of issues before they participate in a weekend of (balanced) briefings by experts, discussion amongst participants and questioning of experts, politicians and stakeholders. The sample is then re-interviewed at the end of the period of deliberation (see Fishkin 1997 or Luskin, Fishkin and Jowell 2002 for a detailed account of the methodology). Fishkin has argued that combining probability-based sampling with the increased information, attention and deliberation that respondents bring to the 'post' survey reveals "the views the entire country would come to if it had the same experience of behaving more like ideal citizens immersed in the issues for an extended period" (Fishkin 1997, p. 162). And, following the successful conduct of nearly twenty deliberative polls in at least seven different countries, there can be little doubt that the method consistently engenders sizeable net and gross opinion change across a range of issues and political contexts (Merkle 1996; Fishkin 1997; Luskin, Fishkin and Jowell 2002; Hansen and Andersen 2001).

Yet, while we may be impressed by the shifts in marginal totals which undoubtedly accompany the welter of information and increased attention respondents pay to the topic, can we really be sure that we are uncovering 'enlightened preferences' - the attitudes people would have held had they always been as involved in and informed about the issues? Would the same results have been obtained on a different sample? Or, perhaps more to the point, would the same sample have responded differently to a different set of speakers or a slightly modified set of briefing materials? The predominant focus on simple input-output effects means that the complex and interacting causal mechanisms underlying opinion change in the deliberative poll - public and private deliberation, informational influence, group dynamics and persuasion - remain unclear, leaving the deliberative poll as something of an explanatory 'black box' (Price and N eijens 1998). 
Price and N eijens (1997) have set out a framework for evaluating the 'quality' of measures of opinion, which links 'opinion quality' to notions of democracy and social choice. Such a formulation fits well with Fishkin's own conceptualisation of the deliberative poll as being intended as "more than a social science experiment; it is also meant to contribute to the public dialogue" (Fishkin 1997, p189). One of the key 'outcome-oriented' hallmarks of 'considered' opinions, from this perspective, is the extent to which attitudes are consistent with beliefs about the implications and consequences of different courses of action (Yankelovich 1992) and with other idea elements within the belief system as a whole. The idea of consistency as an indicator of opinion quality draws us, in turn, into the longstanding tradition of Political Belief Systems (PBS) research and Converse's notion of attitude 'constraint'.

\section{ATTITUDE CONSTRAINT}

The concept of attitude constraint derives from the idea that attitudes toward specific areas of government policy are structured by more abstract value dimension(s) further back in a hierarchical system of belief (Converse 1964; Peffley and Hurwitz 1985). Thus, though not necessarily logically related, we should expect a degree of correspondence between the position an individual takes on issue $A$ and the position they take on issue $B$, to the extent that both articulate with higher order values and beliefs. Converse invokes the analogy of 'glue' to convey his idea of attitudinal constraint, a cognitive binding agent which, both vertically and horizontally, integrates idea elements into a coherent and, in some senses, unitary cognitive entity. The idea that a particular belief 'goes with' another should not, however, be seen as syllogistically proscriptive but as reflective of the historical and cultural influences brought to bear on the social and political fabric of a given society at a particular point in time - together with the 'idiosyncratic twist' engendered by the individual's own experiential history.

More information and greater internal integration of idea elements are indicative of greater political sophistication (Luskin 1987). More sophisticated individuals, it is proposed, experience greater political efficacy; ideological organisation affords straightforward assimilation and retention of novel information and provides a meaningful framework through which it is possible to assess the optimal course(s) of action to achieve one's instrumental objectives. Ultimately, organisational structure and parsimony aids individual efficacy by facilitating the development of attitudes and partisan tendencies which are more in line with individual and group interests (Mansbridge 1983; Bartels, 1996; Althaus 1998).

The empirical observation that first led to the development of the constraint construct was the steep gradients in correlations between attitude items that emerged across virtually any measure of cognitive elaboration or information capacity (Converse 1964; 1990). The over-arching aim of the 
tradition of research into attitude constraint has, consequently, been to delineate the social and psychological mechanisms underlying such gradients. Revisionist critiques of Converse's pessimistic model of the public's political acumen have variously focused attention on measurement error (Achen 1975; Erikson 1979); historical changes in political climate ( $\mathrm{Nie}$ and Anderson 1974; $\mathrm{Nie}$ and Verba 1975; Nie et al 1979); and the application of an inappropriate methodological paradigm (Lane 1962; Rosenberg 1988) to counter the main thrust of Converse's 1964 position. In our view, such responses have failed to decisively overturn Converse's original conclusions on the causes of gradients in constraint but space precludes their closer examination here (though see Kinder and Sears 1985; Kinder 1998; and Converse 2000 for comprehensive reviews). Instead we focus our attention on Converse's original model of ideological constraint, which ties correlational gradients to differences in the level of information and ideological sophistication that individuals bring to attitude questions in surveys.

\section{THE ANTECEDANTS OF CONSTRA INT}

For Converse, lower inter-item correlations amongst the less politically informed are essentially a result of the combined influence of two main characteristics of the belief systems of this group; the weak, uncognized 'nonattitudes' that underpin responses to individual survey items and the lack of coherence with relation to higher order organising principles in the belief system as a whole. The two are undoubtedly strongly and inextricably related, opposite sides of the same coin, if you like. Nonetheless, it is important to distinguish between the distinct mechanisms through which political knowledge impacts on belief system structure, for the effects of these two mechanisms may in some instances be confounded.

We turn first to the relation between knowledge and deliberation on the one hand and the reliability of individual items on the other, and how this concomitantly impacts on observed levels of association between the items in question. To the extent that 'nonattitudes' are 'top-of-thehead' responses to uncognized stimulus objects, we might reasonably expect that increases in information would lead to more considered, stable attitudes that have been arrived at through rational, preference-based judgements. In the language of signal detection theory, we would expect the ratio of signal to noise for individual items to increase with greater political knowledge. In the aggregate, this would reduce the random component in the respective survey items for more knowledgeable groups of respondents, disattenuating the magnitude of correlation between them (Bollen 1989), holding constant the actual level of association between items.

As a second consequence of increasing knowledge and deliberation, we might also expect that individuals obtain a better understanding of 'what goes with what' (and why) and that this too would feed through into stronger inter-item associations at the aggregate level. This is perhaps the more 
common understanding of how knowledge and deliberation impact upon statistical associations between attitudes and has also been the source of some objection to the idea that more sophisticated individuals should always have more 'consistent' belief systems (Lane 1962; Rosenberg 1988). It is important to note, however, that the general idea being outlined here is not equivalent to stating that increasing sophistication will always result in stronger linkage between issue domains; increased differentiation may equally well be the hallmark of sophistication in a specific context. As Luskin (1987) points out, it is a common mistake amongst public opinion researchers to conflate correlation and consistency when investigating the concept of constraint.

Whether sophistication leads to association or differentiation across a set of political issues is, therefore, an empirical question. While conceding, however, that increased consistency will not always result from greater knowledge and deliberation, we must pit this observation against the extreme regularity with which measures of statistical association appear to adopt an upward gradient when stratified by virtually any indicator of political sophistication (A berbach et al 1981; Butler and Stokes 1974; Converse and Pierce 1985; Bartle 2000; Sturgis 2001). So, while it would certainly be possible for a differentiation effect to over-ride disattenuation of inter-item correlations through reduced measurement error, it would seem likely that this would be restricted to a minority of cases in the real world.

\section{AN INTEGRATIVE MODEL}

Zaller and Feldman (1992) provide an explicit theoretical formalisation of these ideas which integrates measurement error and consistency perspectives on attitude constraint and explains how greater familiarity with political issues impacts on a range of survey response characteristics which have traditionally been taken as indicators of sophistication: context effects (Schuman and Presser 1981); response stability; and inter-item association. Zaller and Feldman propose a 'Simple theory of the Survey Response' which conceives attitudes, not as preformed cognitive entities waiting to be recovered fom some mental filing cabinet, but as temporary constructions which are both time and context dependent. For Zaller and Feldman the fundamental building blocks in the construction of 'revealed preferences' (as they term survey attitude responses) are 'considerations' and 'predispositions'. While the latter are in many respects akin to the notion of core beliefs and values (Rokeach 1973; Feldman 1988), determining the favourability an individual will accord to a particular proposition or idea, the former are bits of information which, depending on their predispositions, will incline a respondent to "decide a political issue one way or another" (Zaller 1992, p. 21). Zaller and Feldman delineate their theoretical framework with a set of axioms concerning the acquisition, retention and weighting of considerations to enable the derivation of testable hypotheses about survey responses: 
The reception axiom : the more involved and engaged an individual is with politics, the more likely they are to acquire new considerations.

The resistance axiom: people resist incoming information that is inconsistent with their predispositions but only to the extent that they possess sufficient considerations to perceive such inconsistencies.

The accessibility axiom: the more accessible a consideration is in memory, the more easily it and related considerations will be retrieved. Accessibility itself depends on contextual factors and the recency with which considerations were in conscious memory.

The response axiom: survey responses are derived by averaging over accessible considerations.

These axioms allow certain clear deductions about how different people will respond to survey questions: people who are more interested and involved in politics will have a deeper pool of considerations from which to infer their attitudes. They will also, according to the resistance axiom, have less contradictory considerations because they will be better able to recognise information that conflicts with their predispositions and resist its persuasive influence. Finally, when they are called upon to provide an attitude response in a survey, they will be averaging over a larger pool of more consistent considerations than the less politically aware, which results in the same response alternative being selected more consistently over time. Their attitudes are also more consistent with one another at any one point in time due to the combined influence of the reception and resistance axioms; they are more likely to seek out and obtain new information and, as their stock of relevant considerations grows, to resist information that conflicts with their predispositions. The net effect is a larger pool of consistent considerations, or in other words, more constrained attitude systems. Low levels of knowledge produce labile, situationally dependent responses which, in turn, produce lower correlations with other attitude items.

While the literature is now replete with confirmations of the deduction from this model that less knowledgeable citizens should exhibit lower statistical associations between attitude items (see Sinnott 2000; Bartle 2000 for recent examples), we are unaware of any extant experimental or quasiexperimental investigations of the hypothesis. Yet, so long as we rely entirely on cross-sectional data, the real possibility remains that it is something other than information, involvement and deliberation that is causing gradients in correlational measures of constraint. By examining whether changes in these variables at time 1 are followed by changes in constraint at time 2 we are able to gain much greater leverage on the relation between sophistication and constraint. Indeed, Fishkin has himself 
argued that increased belief system consistency should be apparent after participating in a deliberative poll:

"M any ... nonattitudes and pseudo-opinions would be replaced by views that are better rationalized and supported and perhaps more consistent with other el ements in the respondent's belief system"

Fishkin (1991 p.83)

In the remainder of the paper we, therefore, turn our attention to an evaluation of the evidence from five UK deliberative polls that increases in knowledge, involvement and deliberation lead to a subsequent growth in statistical measures of constraint.

\section{DATA}

In collaboration with James Fishkin, the Independent Newspaper and Channel 4 Television, the National Centre for Social Research ${ }^{1}$ conducted five deliberative polls in the UK during the late 1990s which form the bases of our analyses in this paper. The polls covered attitudes toward crime and criminal justice (1994); European integration (1995); the Monarchy (1996); issues around the 1997 General Election (1997); and the National Health Service (1998). All five polls had the same basic design - a stratified, multi-stage probability sample of individuals in Great Britain was drawn from the Electoral Register, with the aim of obtaining approximately one thousand face-to-face interviews. Respondents to this baseline survey completed a self-completion questionnaire containing items of relevance to the topic area and a range of standard demographic questions. Respondents to this stage of the study were invited to attend the weekend of 'deliberation' at a central location, with all expenses covered and a small monetary incentive. Between the interview and the event itself participants were sent briefing documents about the issue in question, outlining as impartially as possible the main points of contention. At the weekend event, participants were 'immersed' in the issues both in small, moderated groups and in plenary sessions, where specialists representing different perspectives presented their views and answered questions. Further plenary sessions were presented by prominent politicians, usually Secretaries of State and their shadow counterparts. At the end, participants completed the self-completion questionnaire once again. The whole event was televised, in edited form, on Channel 4 on the Sunday evening of the deliberative weekend.

As set out in table 1 , response rates to the initial survey were around $60-70 \%$, with about a fifth to a third of those responding at this stage eventually participating in the deliberative component of the study. This means that, generally, only around $20 \%$ of eligible respondents drawn for the initial sample actually provided 'before' and 'after' data. Fishkin (1997) and Luskin, Fishkin and Jowell 
(2002), however, report that, despite these low rates of response, the deliberative samples matched the baseline samples across a range of important demographic marginals.

\section{METHOD}

The self-completion questionnaire from each of the five polls was examined to identify every attitude scale with three or more ordinal indicators. This resulted in a total of sixteen attitude scales to form the basis of the analysis. These were distributed across polls as follows: crime (4); Europe (4); Monarchy (4); Election issues (1); and NHS (3). Exploratory Factor Analysis was used to check that a single common factor model was a reasonable representation of the observed data for each scale ${ }^{2}$. Full wordings for all 16 attitude scales are provided in the A ppendix. Having identified these 16 attitude scales, the aim of the analysis was then to determine whether there was any evidence for change in the level of constraint between items across the two waves of the polls.

The matter of how constraint should be empirically operationalised has received a good deal of consideration in the PBS research literature. Much criticism has been levelled at the use of inappropriate correlational statistics such as Goodman and Kruskal's Gamma (Weisberg 1974; Balch 1979; Luskin 1987). Even correlational measures deemed more appropriate to the task are problematic because they conflate slope and the distribution of points about the regression line. This means that the distributional properties of the variables being correlated can be as much the cause of betweengroup differences as the actual level of association between the variables in question (Achen 1982, King 1986, Weissberg 1976).

Furthermore, simply comparing averaged, sign-adjusted correlation coefficients across a matrix of variables suffers from at least two significant problems. First, as this technique usually involves either pair-wise or listwise deletion of missing cases, with levels of missing data on these types of attitudinal variables often rising as high as $10-30 \%$ of eligible cases, the effects of non-random item missing data can lead to substantial over-estimates of constraint3 (Bennett, et al. 1979). Second, the historical lack of parametric statistical tests for differences in these averaged coefficients means that comparing levels of constraint between groups, while of some descriptive value gives us no idea of what constitutes a large or a small, let alone statistically non-zero difference between groups.

Multivariate correlational methods such as Exploratory Factor Analysis (EFA) have also been used to examine the relatedness of individual issues and dimensionality of belief systems within the general

\footnotetext{
${ }^{1}$ Formerly Social and Community Planning Research (SCPR).

2 This was done by examining the elbow of scree plots of eigenvalues rather than selecting an arbitrary cut-off point for eigenvalues. That a single factorial structure underlay each attitude scale was desirable because this is an assumption underlying Cronbach's Alpha which we use in later analyses.

3 The direction of the bias is toward overestimates as it is the least politically involved and therefore the least ideologically constrained sample members who are most likely to provide item missing data (Smith 1984).
} 
public (Himmelweit, et al. 1985, Jackson and Marcus 1975, Stimson 1975). In terms of political sophistication, the rationale underlying these factor analytic approaches is that, to the extent that belief systems are more constrained, the factorial structure should be simpler and the percentage of variance explained greater, the more sophisticated the individual's political thinking. While this general hypothesis has, to some extent, accrued empirical support (Stimson 1975; Delli Carpini and Keeter 1996), there is a lack of consensus as to whether more constrained belief systems should always result in simpler factor structures (see Luskin 1987). Furthermore, solutions for exploratory factor analyses are heavily determined by issue content and the number of variables included in the analysis, which makes it difficult to argue that such inductive approaches reflect the true ideological structuring of belief systems in the mass public (Rosenberg 1988).

More recent treatments of constraint have moved away from bivariate correlational measures and EFA and adopted Confirmatory Factor Analysis (CFA) or its extension - Structural Equation Modeling (Joreskog 1973, Joreskog 1993, Joreskog and Sorbom 1989). Judd and Milburn (1980, see also Judd, et al. 1981) have argued that, in conjunction with measures of overall model fit, the pattern of unstandardised factor loadings between each indicator variable and the latent construct it measures may be taken as indicative of the level of belief system constraint in a population. Using the unstandardised coefficients, they argue, avoids the potential problem of unequal variances in the observed variables across groups causing spurious differences in constraint in standardised measures. However, as both Martin (1981) and Converse himself (1980) have argued, unstandardised factor loadings are not particularly useful measures of constraint because they do not represent absolute magnitudes but are meaningful only relative to the factor loading that is fixed to unity in order to set the scale of the latent variable. They argue that differences across groups in standardised parameters and measurement errors of the observed variables are more informative indicators of the internal coherence of political belief systems.

In this study we combine a simple correlational measure of attitude constraint - Cronbach's Alpha with recent innovations in the estimation of sampling variance through the bootstrap (Efron 1979; 1982). Alpha essentially gives the average, sign-adjusted correlation between items, with an upward correction for each additional item included in the scale (Cronbach 1951). We chose Cronbach's Alpha as our operationalisation of constraint, despite its relative lack of technical sophistication, because it is such correlational measures that have traditionally been and continue to form the basis of empirical research into constraint as a measure of political sophistication. By applying the bootstrap to estimates of differences in Alpha within and between groups, it is possible to perform statistical tests of differences in coefficients, where previous examinations of gradients in such correlational measures have tended to rely on 'eyeballing' and intuition. Our simple test of significant difference in all the 
analyses that follow is whether the bootstrapped $95 \%$ confidence interval of the difference in Alpha crosses zero.

In addition to testing for differences in constraint before and after deliberation for the whole sample, we wished to examine whether the effect of information and deliberation on constraint was moderated by extant knowledge levels. All five polls contained short knowledge quiz items in a true/ false format about the issue on which the poll focussed. Raw scores on the knowledge measures were recoded into three bands to form high, medium and low knowledge groups. Tests were performed for differences in Alpha within and between knowledge groups. Full wordings coding details and reliabilities for the knowledge measures are given in the appendix.

Item missing data on the items that form the basis of our analysis here are potentially problematic due to the probable positive correlation between nonresponse propensity and opinion constraint. Listwise or pairwise deletion of missing observations, assuming such a correlation, would militate against detecting increases in constraint, as the initially least constrained respondents (and, therefore, those most prone to increases) would be disproportionately dropped from the analysis. To check for this we imputed all missing data using the EM algorithm (Dempster, Rubin and Laird, 1977) and repeated the analysis with the imputed data. However, this resulted in only minor changes to the unimputed estimates and had no material impact on the substantive conclusions we draw here. For the sake of explanatory simplicity, we therefore present estimates from the unimputed data in the tables that follow 4 .

\section{RESULTS}

Table 2 shows Cronbach's Alpha across knowledge groups for the baseline sample at wave one and the weekend sample at waves one and two for the Election Issues Poll. The baseline sample estimates have a base of all respondents to the baseline survey, while the weekend sample estimates are based on just those respondents who participated in the weekend of deliberation. Tests for differences in Alpha between the baseline and weekend samples are calculated on the group who didn't attend the weekend compared to those that did.

\section{TABLE 2ABOUT HERE}

Table 2 shows the familiar upward gradient in statistical consistency by level of political knowledge for the baseline sample, though only the difference between the low knowledge group and the other two groups reaches statistical significance at the $95 \%$ level of confidence. While still just about visually

\footnotetext{
${ }^{4}$ Contact corresponding author for details of the imputed estimates.
} 
apparent amongst the weekend sample, the difference between groups is much reduced and does not reach statistical significance 5 . The alpha coefficient for the weekend sample is some seven points higher than for the baseline sample, though again, this difference is not statistically significant. For the whole weekend sample, al pha increased over the course of the weekend but only marginally and nonsignificantly. Neither was there any evidence that an effect was moderated by existing knowledge level with all groups showing no detectable change over the weekend. From the election issues poll then, there is little evidence of an increase in constraint, albeit that only one attitude scale was amenable to analysis in this data set.

Turning next to the crime poll data, Table 3 sets out the same breakdown for the four scales identified in this dataset. Two of the scales show a significant upward gradient in coefficients by knowledge group amongst the baseline respondents while two show no discernible pattern. The gradient in scales 1 and 2 remains visible amongst the weekend sample at wave one, although not so consistently and without reaching statistical significance. On attitude 1, the weekend sample had a significantly higher coefficient than respondents who did not participate in the weekend poll, perhaps reducing the potential for increase over the course of the weekend. On attitudes 3 and 4 there was no upward gradient in coefficients, attitude 4 exhibiting a significant downward gradient across knowledge groups in the weekend sample.

\section{TABLE 3ABOUT HERE}

In terms of change before and after the weekend, Table 3 shows a significant increase in Alpha for attitude 2, an effect that was also found within the low and high knowledge groups on these items. Attitudes 1 and 3 showed no overall or within group change, while attitude 4 showed a significant increase in Alpha amongst the high knowledge group only. At wave two there were no significant differences in Alpha between knowledge groups, perhaps indicating some sort of equalising effect of information and deliberation upon constraint.

Table 4 shows the results of the analysis on the Monarchy poll data. Of the four attitudes studied, only one showed any sign of a gradient in coefficient Alpha at wave one, in both the baseline and the weekend samples; the medium knowledge group on attitude 4 was significantly lower than both the low and high knowledge groups. Only one of the attitude scales, attitude 1, showed any change in Alpha over the weekend, the coefficient for the whole sample increasing from .55 to .71 . This pattern

\footnotetext{
5 It is worth noting at this juncture, the limited power to detect between and within group differences in samples sizes typically achieved in deliberative polls (see Sturgis 2001). While effects of any substantive magnitudeshould bedetedablefor inferences to the total population, as soon as attention focuses on sub-groups of interest, sample sizes soon drop to levels where it is quite likely that meaningful differences and change over time will not be significant at conventional confidence levels.
} 
was mirrored within all three knowledge groups for this set of items, although only the change in the low knowledge group was statistically significant.

\section{TABLE 4ABOUT HERE}

Results of the analysis on the European integration poll data are shown in Table 5. All four attitude scales show a significant upward gradient in Alpha coefficients across knowledge groups for the baseline sample. The general pattern is still apparent for the weekend sample, but with some anomalies and without consistently reaching statistical significance, probably because of the reduced power for detecting effects in these smaller size groups. Although none of the coefficients are significantly different within knowledge groups between those who did and those who did not attend the weekend at wave one, there are some marked differences in the pattern and magnitude of coefficients between these samples. The low knowledge group on attitudes 2, 3 and 4, for instance, is markedly higher in the weekend sample than amongst those who did not participate in the deliberations.

\section{TABLE 5ABOUT HERE}

In terms of change, the pattern in the European issues poll is more consistent, with three of the four sets of items showing an increase in Alpha over the weekend for the sample as a whole. For attitude 1 this increase was predominantly concentrated within the low knowledge group, while for attitude 3 the change was mainly confined to those in the medium knowledge group. For attitude 4 , the increase was consistent across groups, though none reached statistical significance at the $95 \%$ level of confidence. Three significant between group differences remained at the end of the weekend, with the high knowledge group having significantly the largest A lpha on attitudes 1, 2 and 3.

Table 6, shows the results for the fifth and final poll on attitudes toward the National Health Service. In attitudes 1 and 2, there is a gradient in Alpha coefficients but this is a downward gradient, with the low knowledge group having the highest coefficient, though this is only statistically significant on the weekend sample for attitude 2. On attitude 3 there is a partial upward gradient with the high knowledge group showing a significantly higher coefficient than the low knowledge group in the baseline sample but not in the weekend sample.

\section{TABLE 6ABOUT HERE}


There were no significant changes in Alpha for the overall sample over the course of the weekend but, for attitudes 1 and 2, the low and medium knowledge groups showed a significant decline in scale reliability. By the second wave of measurement, no significant differences remained between groups.

Perhaps the one clear thing that is immediately apparent from this set of results is that there is no clear or consistent pattern discernible across studies. While the majority of studies exhibited an upward gradient in coefficients by knowledge group amongst the full wave one sample, a significant minority did not and several showed a gradient in the opposite direction. The predominant trend, in relation to our main research hypothesis, was no change in consistency over the course of the weekend. On the other hand, six out of sixteen attitude scales did show a significant shift - considerably more than chance alone would predict. However, two of these changes were in a downward direction, the opposite of what our theoretical model would lead us to expect. And, although there was some evidence to support the idea that existing knowledge level mediates the magnitude of change in attitude consistency, no clear pattern emerged across the studies examined to show what the functional form of this relationship might be.

\section{A META-ANALYSIS}

In order to provide a more satisfactory summary of these somewhat disparate findings, we conducted a meta-analysis of the sixteen attitude scales across all five studies. M eta-analytic techniques see effect sizes estimated from single studies as units drawn from a hypothetical population of possible studies. As such, relying on single studies for effect size estimates relies on the unlikely event that the single study is representative of all possible studies that could have been sampled from this population (Rosenthal 1991). The basic objective of meta-analysis is, therefore, to provide pooled estimates of effect sizes through a weighted average of the effect sizes of the individual studies (Hall et al 1994). A key aspect of any meta-analysis is, therefore, to conduct a thorough search of all extant studies which should then be included in the pooled estimate (Wolf 1986). In the current instance, this requirement can only be satisfied by extending the scope of the study or by limiting the population of inference to those polls conducted in the UK, admittedly a somewhat expedient and artificial restriction. Nonetheless, we have no theoretical or empirical reason to expect that the effect sizes in deliberative polls should vary widely across countries and restricting our leverage in this way allows a convenient summary of what is certainly a rather disparate set of individual study results.

Effect sizes can be pooled across studies assuming either fixed or random effects. A fixed effects model assumes that the variability in effect sizes across studies is exclusively due to random variation and that, with sufficiently large sample sizes, all studies would provide identical estimates. A random effects model assumes heterogeneity of effects across studies and incorporates this additional source of variation in the pooled effect size estimate. This usually results in wider confidence intervals than a 
fixed effects model fitted to the same data. In the tables that follow, all estimates are derived from random effects models, making our estimate of variability across studies quite liberal 6 .

Table 7 shows the pooled effect size for the difference in Alpha between those who did and those who did not attend the deliberative weekend. One of the main lines of criticism of the validity of the deliberative poll methodology has been that those who participate in the weekend of deliberation will likely differ in important ways from the general population, despite matching on broader demographic citeria (Mitofsky 1996a; 1996b; Tringali 1996). The non-significant difference in Alpha between samples, if we can accept this operationalisation of the constraint construct, indicates that attitude constraint is not such a variable. It also suggests that the general lack of over-time change is unlikely to be as a result of biases in the composition of the samples examined here.

\section{TABLE 7ABOUT HERE}

Table 8 shows the pooled effect sizes for differences in Alpha between knowledge groups, for the whole baseline sample and the weekend sample at waves one and two. The familiar gradient in coefficients with increasing knowledge is discernible for the baseline sample, although the difference between medium and low knowledge groups does not reach statistical significance. The numbers, in absolute terms, are certainly not large but the upward pattern is clear. For the weekend sample at wave 1 , the general pattern remains, although not significantly and the suggestive difference between medium and low knowledge groups in the baseline sample has disappeared completely. This may well be as much the result of our imposition of too fine a gradation in knowledge groups for a sample of this size, as to actual differences between 'groups'; it may be the case that a better characterisation of the knowledge gradient for the scales in question would be between those high and low in knowledge, omitting a 'medium' category entirely.

\section{TABLE 8ABOUT HERE}

Interestingly, at wave two, the weekend sample return to the pattern observed amongst the baseline sample, with the high knowledge group exhibiting significantly greater coefficients than both low and medium knowledge groups, al beit at somewhat diminished magnitudes. This perhaps goes some way to dispelling the notion that the deliberative weekend acts as some kind of 'equalising' force and lends support to the idea that more politically sophisticated individuals process and integrate information more efficiently than their less sophisticated counterparts (Krosnick and Milburn 1990; Delli Carpini

\footnotetext{
${ }^{6}$ Random effects models are generally preferred when statistical tests indicate that there is significant effect size heterogeneity across studies, which was generally, though not always, the case in the analyses conducted here.
} 
and Keeter 1996; Althaus 1998). By providing information in this 'avalanchelike' manner, the possibility exists that we may actually be widening the gap we are intending to broach.

Moving now to a consideration of our main research hypothesis, Table 9 shows the pooled estimate of the change in Alpha between waves one and two, for the weekend sample as a whole and within each of the extant knowledge groups. The $95 \%$ confidence intervals show that only the pooled estimates for the sample as a whole and the high knowledge group are statistically significant. The average magnitude of the increase across all studies was only 0.024 , a difference that would be unlikely to strike the average reader as of particular substantive interest. However, the significant value of $Q$ for the test of heterogeneity of effects across studies indicates that, as we saw in the results of the individual polls, this average figure masks a good deal of variation across issues and studies. Clearly then, the deliberative process can have exactly the effect that Converse and Zaller and Feldman's models would lead us to expect.

\section{TABLE 9ABOUT HERE}

Finally, there is no evidence in Table 9, to suggest that the impact of the deliberative process on correlational measures of attitude constraint is somehow moderated by existing level of knowledge about the issue in question. The pooled effect sizes show moderate increases in coefficients, on the fringes of statistical significance which areal most identical across the three knowledge groups.

\section{DISCUSSION}

The aim of this paper has been to exploit the unusual features of the deliberative polling methodology to explicitly test the hypothesis that the low inter-item correlations commonly observed amongst the politically less informed members of the public are caused by a lack of information about the objects of their attitudes. This has been the implicit rationale underlying the many studies that have demonstrated a steep upward gradient in the magnitude of inter-item correlations with increasing political interest, involvement and knowledge. If this rationale is correct, we should expect to see increases in the magnitude of statistical associations between attitude items following a weekend in which political issues and preferences have formed the focus of deliberation and debate. Such measures of 'opinion quality', in addition to the observation of net and gross attitude change, are also necessary for a proper evaluation of the claims made for deliberative polls as a means of uncovering 'enlightened preferences' (Price and Neijens 1997; 1998). Was the significant change in attitude and knowledge after deliberation in these studies (Fishkin 1997; Luskin, Fishkin and Jowell 2002; Sturgis 2003), then, accompanied by concomitant increases in the internal consistency of respondents' attitude systems? 
Across five different deliberative polls, sixteen attitude scales, comprising ninety seven individual items the evidence for such an effect was both patchy and inconsistent. While some polls appeared to show a rather strong and consistent pattern confirming the expectation that statistical associations between items would increase after deliberation (the Europe poll), others showed no change at all (the election issues poll), and others still showed a downward movement (the NHS poll), the opposite of what our theoretical model would lead us to expect. Clearly then, if it is knowledge, deliberation and engagement that cause gradients in correlational measures of constraint in cross-sectional surveys - a finding broadly replicated in the data studied here, the deliberative poll would not appear capable of consistently reproducing the direction and magnitude of the effect over the relatively short period involved.

A potential barrier to the acceptance of this conclusion is the issue of whether the before and after samples are truly representative of the general population. Perhaps the main feature of deliberative polling which sets it apart from other 'deliberative' methodologies such as citizens' juries and planning cells, is its probabilistic design and consequent generalisability of the achieved sample. Investigations of the representativeness of deliberative poll samples have, thus far, been based primarily on demographic characteristics such as age, sex, education and social class, variables which appear to match population totals with impressive closeness (Fishkin 1997; Luskin, Fishkin and Jowell 2002). As with quota sampling, however, such equivalence does not guarantee representativeness across all survey variables. A genuine and plausible concern is that it is the more politically sophisticated individuals from within these demographic groups that tend disproportionately to participate in deliberative polls (Tringali 1996; Sturgis 2001). In the current instance, this might militate against finding evidence of increasing constraint, if the participants are already amongst the more politically sophisticated and, therefore, constrained members of the public. The evidence from the analyses presented here do not support this hypothesis; on only one of sixteen attitude scales was there a significant difference between the baseline and weekend samples in the level of constraint, as we have operationalised it here. On a broader and more general measure of sophistication, then, there would appear to belittle evidence of bias in these deliberative poll samples.

Given the disparate nature of the effects across the five studies, a meta-analysis was conducted to determine whether any general pattern could be dscerned statistically, as opposed to visually and impressionistically, across studies. This revealed that, taken together, the polls exhibited a modest but statistically significant increase in constraint over the course of the weekend, confirming - if somewhat weakly - the main research hypothesis we set out to evaluate. There was no evidence to suggest, however, that this effect was differentially related to respondents' knowledge level prior to the weekend of deliberation as effects were uniform across the knowledge groups examined. In drawing such conclusions, it is as well to remember that the sample sizes we are dealing with do not afford a 
great deal of power to detect systematic effects, a fact which is likely to be partially responsible for some of the apparently contradictory findings we have reported. The pooled effect size estimate of change in Alpha over the weekend masked statistically significant heterogeneity across the individual study elements. This would seem to offer a fruitful avenue for future research - by incorporating variables that differentiate between polls and attitudes in this type of meta-analysis, it should be possible to begin to explain what it is about particular issues and political contexts that leads to differential effects.

While the results for the whole sample analysis, then, indicate a slight increase in the degree of internal consistency of attitudes over the course of the weekend, this must be placed in the context of findings from similar models fitted to panel surveys with no specific 'information intervention' between waves, for what we lack in the analyses conducted here is any form of control group. We are, as a result, unable to disentangle the effect of increased information and deliberation from that engendered by simply participating in two waves of a panel study. Jagodzinski et al (1987), for example, find an average increase in item reliabilities of $19 \%^{7}$ between waves one and two on a four item scale measuring attitude toward guest workers in West Germany, an effect they attribute to the simple fact that "related or logically interdependent issues appear to stimulate respondents to reflect on the relations between their attitudes, opinions and behaviour" (Jagodsinski, et al. 1987, p.260). On a six item scale measuring 'left-right' political orientation, a 10\% increase on the same parameter was observed between waves one and two of the British Household Panel Study (Sturgis, 2001). If this is the effect of simply being administered a questionnaire, then we would surely expect the effects of attending a deliberative poll to be substantially greater.

Such comparisons lead us to conclude that the evidence we have presented here cannot be taken as showing that participation in deliberative polls leads to increases in constraint, as this construct has traditionally been operationalised. This general conclusion must be qualified, however, by noting that such an effect is certainly a possible, even a probable outcome of the deliberative polling process for any given issue. The way forward for research in this area would seem, then, to be a careful delineation of the characteristics of issues, sample designs and political contexts which predict whether increased knowledge and deliberation result in a corresponding growth in attitude constraint.

\footnotetext{
7 Our own calculation from Table 3, page 292 (Jagodzinski et al. 1987).
} 


\section{REFERENCES}

Aberbach, J., Puttnam, R. and Rockman, B. (1981) Bureaucrats and Politicians in Western Democracies. Cambridge, Massachusetts: Harvard University Press.

Achen C (1975) Mass Political Attitudes and the Survey Response. A merican Political Science Review 69(1218-23).

Achen, C. (1982) Interpreting and using regression, Beverly Hills, Sage.

Althaus S (1998) Information Effects in Collective Preferences. A merican Political Science Review 92(3), 545-558.

Asher, H. (1974) Some Consequences of Measurement Error in Survey Data. A merican Journal of Political Science 18: 469-485.

Balch G (1979) Statistical Manipulations in the Study of Issue Consistency: The Gamma Coefficient. Political Behaviour 1,217-41.

Bartels L (1996) Uninformed Votes: Information Effects in Presidential Elections. A merican Journal of Political Science 40(1), 194-230.

Bartle J (2000) Political Awareness, Opinion Constraint and the Stability of Ideological Positions. Political Studies 48, 3, pp. 467-484

Barton A and Parsons R (1977) Measuring Belief System Structure. Public O pinion Quarterly 41,159-80.

Bennett S (1988) "Know-Nothings" Revisited: The Meaning of Political Ignornance Today. Social Science Q uarterly $17,422-35$.

Bennett S, Oldendick R, Tuchfarber A and Bishop G (1979) Education and Mass Belief Systems: An Extension and some new Questions. Political Behaviour 1, 53-71.

Bollen, K.A. (1989). Structural Equations with Latent V ariables. NY: Wiley.

Butler D and Stokes D E (1969) Political change in Britain : forces shaping electoral choice. Macmillan, London.

Butler D and Stokes D E (1974) Political change in Britain : the evolution of electoral choice.(2nd edition) Macmillan, London.

Campbell A, Converse P, Miller W and Stokes D (1960) The A merican V oter. John Wiley, N ew York.

Converse P (1964) The Nature of Belief Systems in Mass Publics. In Ideology and Discontent (D. A ed.) Free Press, New York.

Converse P (1975) Some Mass Elite-Contrasts in the Perception of Political Spaces. Social Science Information 14,49-83.

Converse P (1980) Comment: Rejoinder to Judd and Milburn. A merican Sociological Review 45,644-46.

Converse, P. and Pierce, R. (1985) Political Representation in France. Cambridge, Mass.: Harvard University Press.

Converse P (1990) Popular Representation and the Distribution of Information. In Information and D emocratic Processes (Ferejohn A and Kuklinski J eds.) University of Ilinois Press, Urbana. 
Converse, P. (2000) Assessing the Capacity of Mass Electorates. Annual Review of Political Science (3), 331-353.

Coote, A. \& Lenhaglan, J. 1997Citizens' Juries: From Theory to Practice. IPPR, London.

Cronbach L.J. (1951). Coefficient Alpha and the Internal Structure of Tests. Psychometrika, 16, 297-334.

Delli Carpini M X (1985) Stability and change in A merican politics : the coming of age of the generation of the 1960s. N ew York University Press, New York.

Delli Carpini M X and Keeter S (1996) What Americans know doout politics and why it matters. Yale University Press, New Haven [Conn.].

Dempster, Arthur Laird, Nan and Rubin, Donald (1977) Maximum Likelihood Estimation from Incomplete Data via the EM Algorithm. Journal of the Royal Statistical Society, M ethodological Series B, 39: $1-38$.

Eagly A and Chaiken S (1993) The Psychology of Attitudes. Harcourt Brace Jovanovich, San Diego, CA and Fort Worth, TX.

Efron, B. (1979). Bootstrap methods: another look at the jackknife, A nnals of Statistics 71-26.

Erikson R (1979) The SRC Panel Data and Mass Political Attitudes. British Journal of Political Science 9,89-114.

Erikson R and Luttberg N (1973) A merican Public O pinion: Its Origins, Content and Impact. Wiley, New York.

Feldman S (1988) Structure and Consistency in Public Opinion: The Role of Core Beliefs and Values. A merican Journal of Political Science 32,416-440.

Fishkin (1991) Democracy and D eliberation: N ew Directions for Democratic Reform. Yale University Press, New Haven, CT.

Fishkin J (1995) The Voice of the People: Public O pinion and D emocracy.(1st) Yale University Press, New Haven, CT.

Fishkin J (1997) The Voice of the People: Public O pinion and Democracy.(2nd) Yale University Press, New Haven, CT.

Gilens, Martin (2001) Political Ignorance and Collective Policy Preferences. A merican Political Science Review 95 (2): 379-396.

Heath A, Evans G and Martin J (1993) The Measurement of Core Beliefs and Values: The Development of Balanced Socialist/ Laissez Faire and Libertarian/ Authoritarian Scales. British Journal of Political Science 24,115-133.

Hall, J.A., Tickle-Degnen, L., Rosenthal, R., \& Mosteller, F. (1994). Hypotheses and problems in research synthesis. In H. Cooper and L.V. Hedges (Eds.), The handbook of research synthesis. New York: Russell Sage Foundation. 
Himmelweit H T, Humphreys P and Jaeger M (1985) H ow voters decide : a model of vote choice based on a special longitudinal study extending over fifteen years and the British election surveys of 1970-1983 Open University Press, Milton Keynes.

Hyman H and Sheatsley P (1947) Some Reasons Why Information Campaigns Fail. Public O pinion Quarterly 11,412-23.

Iyengar S (1973) The Problem of Response Stability: Some Correlates and Consequences. American Journal of Political Science 17(4), 797-808.

Jackson T and Marcus G (1975) Political Competence and Ideological Constraint. Social Science Research 4,93-111.

Jagodsinski W, Kuhnel S M and Schmidt P (1987) Is There a "Socratic Effect" in Nonexperimental Panel Studes? Consistency of an Attitude Toward Guestworkers. Sociological M ethods and Research 15(3), 259-302.

Jennings M (1992) Ideology Among M ass Publics and Political Elites. Public O pinion Quarterly 56,419441.

Joreskog K (1973) A General Method for a General Structural Equation System. In Structural Equation M odels in the Social Sciences (Goldberg A and Duncan O eds.) Seminar, New York.

Joreskog K (1993) Testing Structural Equation Models. In Testing Structural Equation M odels (Bollen K and LongJ Seds. ) Sage, London.

Joreskog K and Sorbom D (1989) LISREL 7: A Guide to the Program and A pplications. SPSSInc., Chicago.

Jowell R, Hedges B, Lynn P, Farrant G and Heath A (1993) Review: The 1992 British Election: The Failure of the Polls. Public O pinion Q uarterly 57(2), 238-263.

Judd C and Milburn M (1980) The Structure of Attitude Systems in the General Public: Comparisons of a Structural Equation Model. A merican Sociological Review 45,627-43.

Judd C M, Krosnick J and Milburn A (1981) Political Involvement and Attitude Structure in the General Public. A merican Sociological Review 46,660-669.

Kinder D and Sears D (1985) Public Opinion and Political Action. In The Handbook of Social Psychology (Lindzey G and A ronson E eds. ) (3rd) 659-741, Random House, New York.

Kinder R (1998) Opinion and Action in the Realm of Politics. In The Handbook of Social Psychology (, T. D, Gilbert S, Fiske T, Gardner L and G T eds.) McGraw Hill, Boston.

King, Gary. “H ow N ot to Lie With Statistics: Avoiding Common Mistakes in Quantitative

Political Science," A merican Journal of Political Science, Vol. 30, No. 3 (August, 1986):

Pp. 666-687.

Kreuger R.A. (1988) Focus groups: a practical guide for applied research. London: Sage.

Lane R E (1962) Political ideology : why American common man believes what he does. Free Press, New York.

Krosnick, J. and Milburn, M. (1990) Psychological Determinants of Political Opinionation. Social Cognition 8(1): 49-72. 
Lupia A and McCubbins M D (1998) The democratic dilemma : can citizens learn what they need to know? Cambridge University Press, Cambridge, U.K. ; N ew York.

MansbridgeJ (1983) Beyond A dversary D emocracy. University of Chicago Press, Chicago.

Luskin R (1987) M easuring Political Sophistication. A merican Political Science Review 31,856-99.

Martin S (1981) New Methods Lead to Familiar Results: Comment on Judd and Milburn. American Sociological Review 46,670-75.

Luskin, R Fishkin, J and Jowell, R (2002) Considered Opinions: Deliberative Polling In Britain British Journal of Political Science, 32(3)

McArdle J J and Nesselroade J R (1994) Using Multivariate Data to Structure Developmental Change. In LifeSpan Developmental Psychology: M ethodological Contributions (Cohen S H and Reese H W eds.) Lawrence Erlbaum, Hillsdale, NJ.

McGuire W (1960) Cognitive Consistency and Attitude Change. Journal of Abnormal and Social Psychology 3,345-353.

Merkle D (1996) The National Issues Convention Deliberative Poll. Public O pinion Quarterly 60,588619.

Mitofsky W (1996a) The Emperor Has No Clothes. Public perspective 7(1), 17-19.

Mitofsky W (1996b) It's N ot Deliberative and it's not a Poll. Public Perspective 7(3), 4-6.

Neijens, P. (1987) The Choice Q uestionnaire. D esign and Evaluation of an Instrument for Collecting Informed 0 pinions of a Population. Amsterdam, Free University Press.

Nie N and Anderson K (1974) Mass Belief Systems Revisited: Political Change and Attitude Structure. A merican Journal of Sociology 86(1236-68),

Nie N and Verba S (1975) Political Participation. In Handbook of Political Science (Greenstein F and Polsby N eds. ) Addison-Wesley, Reading: Mass.

Nie N, Verba S and Petrocik J (1979) The Changing American Voter. Harvard University Press, Cambridge.

Northpot $\mathrm{H}$ and Lodge M (1985) The Difference between Attitudes and Nonattitudes in the Mass Public: Just Measurements. A merican Political Science Review 29(2), 291-307.

Page B and Shapiro R (1992) The Rational Public: Fifty Years of Trends in American's Policy Preferences. University of Chicago Press, Chicago.

Peffley M and Hurwitz J (1985) A Hierarchical Model of Attitude Constraint. A merican Journal of Political Science 29,871-90.

Price, Vincent and Neijens, Peter (1997) Opinion Quality in Public Opinion Research International Journal of Public O pinion Research 9: 336-360.

Price, Vincent and Neijens, Peter (1998) Deliberative Polls: Toward improved measures of 'informed' public opinion? International Journal of Public O pinion Research 10: 145-176. 
Renn, O, Stegelmann, H., Albrecht, G Kotte, U. and Peters H. (1984) An Empirical Investigation of citizens' preferences among four energy alternatives.Technological Forecasting and Social Change, $2611-$ 46.

Rokeach M (1973) The N ature of H uman V alues. Free Press, N ew York.

Rosenberg S (1988) Attitude, Belief and Ideology: The Need for New Directions. In Political Reasoning and Cognition: A Piagetian View (Rosenberg S, Ward D and Chilton S eds.) Duke University Press, Durham.

Schuman H and Presser S (1981) Questions and Answers in Attitude Surveys: Experiments on Question Form, W ording and Context. A cademic Press, N ew York.

Sinnott, R. (2000) Knowledge and the position of attitudes to a European foreign policy on the real-torandom continuum. International Journal of Public 0 pinion Research, 12, 113-137.

Smith, Tom W. (1984) Nonattitudes: A Review and Evaluation. In Surveying Subjective Phenomena (Turner C and Martin E eds.) A cademic Press, N ew York Pp 215-255.

Sniderman $\mathrm{P}$ and Tetlock $\mathrm{P}$ (1986) Interrelationship of Political Ideology and Public Opinion. In Political Psychology: Contemporary Problems and Issues (Hermann M ed. ) 62-96, Jossey-Bass, San Francisco.

Stevens J (1995) Confirmatory Factor Analysis of the lowa Test of Basic Skills. Structural Equation M odeling 2(3).

Stimson J (1975) Belief Systems: Constraint, Complexity, and the 1972 Election. A merican Journal of Political Science 19(3), 393-417.

Sturgis P (2001) Political A ttitudes: The Role of Information as a Determinant of Direction, Structure and Stability. PhD Thesis, London School of Economics and Political Science, London.

Sturgis P (2003) Knowledge and Collective Preferences: A Comparison of two A pproaches to Estimating the O pinions of a Better Informed Public Sociological Methods and Research 31(4).

Tringali, Brian (1996) Experimenting with Artificial Democracy. Public Perspective 7(1), 19-20.

van Knippenberg, D. and Daamen, D (1996) Providing information in public opinion surveys: motivation and ability effects in the information-and-choice questionnaire International Journal of Public O pinion Research 8: 70-82.

Wakeford, T. (2003) Citizens Juries: a radical alternative for social research. Social Research U pdate (37).

Weissberg R (1974) Models of Statistical Relationship. A merican Political Science Review 68,1638-55.

Weissberg R (1976) Consensual Attitudes and Attitude Structure. Public 0 pinion Q uarterly 40,349-359.

Wolf, F.M. (1986). M eta-analysis: Q uantitative methods for research synthesis. Newbury Park, CA: Sage.

Yankelovich, D. (1991) Coming to Public Judgement: Making Democracy Work in a Complex World, Syracuse, NY, Syracuse University Press.

Zaller J (1992) The N ature and O rigins of M ass O pinion. Cambridge University Press, New York.

Zaller J and Feldman S (1992) A Simple Theory of the Survey Response: Answering Questions versus Revealing Preferences. A merican Journal of Political Science I36,579-616. 


\section{APPENDIX 1TABLES}

Table 1 Response Rates for Five UK D eliberative Polls

\begin{tabular}{lccc}
\hline \hline \multicolumn{1}{c}{ Poll } & D ate & Initial Sample & D eliberative Sample \\
\hline \hline Crime & 1994 & $869(74 \%)$ & $300(26 \%)$ \\
Europe & 1995 & $900(71 \%)$ & $224(18 \%)$ \\
Monarchy & 1996 & $857(62 \%)$ & $258(19 \%$ \\
Election Issues & 1997 & $1210(64 \%)$ & $276(15 \%)$ \\
NHS & 1998 & $955(66 \%)$ & $228(16 \%)$ \\
\hline \hline
\end{tabular}

Table 2 Cronbach's A Ipha A cross Waves and Knowledge Groups Election Poll

\begin{tabular}{|c|c|c|c|c|c|c|}
\hline Attitude & $\begin{array}{c}\text { Knowledge } \\
\text { Level }\end{array}$ & $\begin{array}{c}\text { Full sample } \\
\text { wave } 1\end{array}$ & $\mathrm{n}$ & $\begin{array}{c}\text { Weekend } \\
\text { sample wave } 1\end{array}$ & $\begin{array}{c}\text { Weekend } \\
\text { sample wave } 2\end{array}$ & $\mathrm{n}$ \\
\hline \multirow[t]{4}{*}{ Attitude1 } & "Low (0-2) & $.533^{\mathrm{MH}}$ & $\overline{c 545}$ & (1.66 & . .62 & 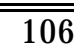 \\
\hline & Medium (3-5) & $.64 \mathrm{~L}$ & 539 & .69 & .74 & 136 \\
\hline & High (6-8) & $.71^{\mathrm{L}}$ & 126 & .70 & .70 & 33 \\
\hline & All & .61 & 1210 & .68 & .70 & 275 \\
\hline
\end{tabular}


Table 3 Cronbach's Alpha A cross Waves and Knowledge G roups Crime Poll

\begin{tabular}{|c|c|c|c|c|c|c|}
\hline Attitude & $\begin{array}{c}\text { Knowledge } \\
\text { Level }\end{array}$ & $\begin{array}{c}\text { Full sample } \\
\text { wave } 1\end{array}$ & $\mathrm{n}$ & $\begin{array}{c}\text { Weekend } \\
\text { sample wave } 1\end{array}$ & $\begin{array}{c}\text { Weekend } \\
\text { sample wave } 2\end{array}$ & $\mathrm{n}$ \\
\hline \multirow[t]{4}{*}{ A Attitude 1} & Low (0-2) & $.50 \mathrm{MH}$ & 244 & .63 & .62 & 69 \\
\hline & Medium (3-5) & $.62^{\mathrm{LH}}$ & 470 & .67 & .69 & 174 \\
\hline & High (6-8) & $.74 \mathrm{ML}$ & 155 & .77 & .70 & 57 \\
\hline & All & .63 & 869 & $.69^{+}$ & .68 & 300 \\
\hline \multirow[t]{4}{*}{ Attitude 2} & Low (0-2) & $.57 \mathrm{H}$ & 244 & .58 & $.75^{*}$ & 69 \\
\hline & Medium (3-5) & $.66 \mathrm{H}$ & 470 & .70 & .76 & 174 \\
\hline & High (6-8) & $.77 \mathrm{ML}$ & 155 & .63 & $.78^{*}$ & 57 \\
\hline & All & .67 & 869 & .68 & $.77^{*}$ & 300 \\
\hline \multirow[t]{4}{*}{ Attitude 3} & Low (0-2) & $.57 \mathrm{H}$ & 244 & .58 & .75 & 69 \\
\hline & Medium (3-5) & $.66 \mathrm{H}$ & 470 & .70 & .76 & 174 \\
\hline & High (6-8) & $.77 \mathrm{ML}$ & 155 & .63 & .78 & 57 \\
\hline & All & .67 & 869 & .68 & .77 & 300 \\
\hline \multirow[t]{4}{*}{ Attitude 4} & Low (0-2) & .72 & 244 & .80 & .71 & 69 \\
\hline & Medium (3-5) & .72 & 470 & .72 & .65 & 174 \\
\hline & High (6-8) & .80 & 155 & .79 & .76 & 57 \\
\hline & All & .74 & 869 & .76 & .70 & 300 \\
\hline \multirow[t]{4}{*}{ Attitude 5} & Low (0-2) & .77 & 244 & .68 & .65 & 69 \\
\hline & Medium (3-5) & .71 & 470 & .77 & .75 & 174 \\
\hline & High (6-7) & .68 & 155 & $.57 \mathrm{M}$ & $.69 *$ & 57 \\
\hline & All & .72 & 869 & .73 & .71 & 300 \\
\hline
\end{tabular}


Table 4 Cronbach's A Ipha A cross Waves and Knowledge G roups M onarchy Poll

\begin{tabular}{|c|c|c|c|c|c|c|}
\hline Attitude & $\begin{array}{c}\text { Knowledge } \\
\text { Level }\end{array}$ & $\begin{array}{l}\text { Full sample } \\
\text { wave } 1\end{array}$ & $\mathrm{n}$ & $\begin{array}{c}\text { Weekend } \\
\text { samplewave } 1\end{array}$ & $\begin{array}{c}\text { Weekend } \\
\text { sample wave } 2\end{array}$ & $\mathrm{n}$ \\
\hline \multirow[t]{4}{*}{ Attitude 1} & Low (0-2) & .55 & 299 & .52 & (75* & 80 \\
\hline & Medium (3-5) & 68 & 195 & .64 & .75 & 52 \\
\hline & High (6-7) & ..56 & 363 & .55 & .63 & 126 \\
\hline & All & .58 & 857 & .55 & $.71 *$ & 258 \\
\hline \multirow[t]{4}{*}{ Attitude 2} & Low (0-2) & .88 & 299 & .87 & .91 & 80 \\
\hline & Medium (3-5) & .84 & 195 & .86 & .85 & 52 \\
\hline & High (6-7) & .88 & 363 & .88 & .90 & 126 \\
\hline & All & .87 & 857 & .88 & .90 & 258 \\
\hline \multirow[t]{4}{*}{ Attitude 3} & Low (0-2) & .89 & 299 & .90 & .91 & 80 \\
\hline & Medium (3-5) & .90 & 195 & .87 & .90 & 52 \\
\hline & High (6-7) & .91 & 363 & .92 & .93 & 126 \\
\hline & All & .90 & 857 & .90 & .92 & 258 \\
\hline \multirow[t]{4}{*}{ Attitude 4} & Low (0-2) & $.59 \mathrm{M}$ & 299 & $.63 \mathrm{M}$ & .63 & 80 \\
\hline & Medium (3-5) & $.42^{\mathrm{LH}}$ & 195 & $.45 \mathrm{LH}$ & .57 & 52 \\
\hline & High (6-7) & $.61^{M}$ & 363 & $.66 \mathrm{M}$ & .64 & 126 \\
\hline & All & .57 & 857 & .59 & .60 & 258 \\
\hline
\end{tabular}

$\mathrm{M}=$ significantly different from Medium Knowledge group; $\mathrm{H}=$ significantly different from High Knowledge group; $\mathrm{L}=$ significantly different from Low knowledge group; ${ }^{*}=$ significantly different from wave $1 ;{ }^{+}=$significantly different from non-weekend sample.

Table 5 Cronbach's A Ipha A cross Waves and Knowledge G roups Euro Poll

\begin{tabular}{|c|c|c|c|c|c|c|}
\hline Attitude & $\begin{array}{c}\text { Knowledge } \\
\text { Level }\end{array}$ & $\begin{array}{c}\text { Full sample } \\
\text { wave } 1\end{array}$ & $\mathrm{n}$ & $\begin{array}{c}\text { Weekend } \\
\text { samplewave } 1\end{array}$ & $\begin{array}{c}\text { Weekend } \\
\text { sample wave } 2\end{array}$ & $\mathrm{n}$ \\
\hline \multirow[t]{4}{*}{ Attitude 1} & Low (0-2) & . $.39 \mathrm{MH}$ & 266 & ".38MH & $.70^{*}$ & 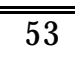 \\
\hline & Medium (3-5) & $.54 \mathrm{LH}$ & 396 & $.59 \mathrm{~L}$ & $.61^{\mathrm{H}}$ & 103 \\
\hline & High (6-7) & $.71 \mathrm{ML}$ & 238 & $.72 \mathrm{~L}$ & $.80 \mathrm{M}$ & 68 \\
\hline & All & .59 & 900 & .60 & $.71 *$ & 224 \\
\hline \multirow[t]{4}{*}{ Attitude 2} & Low (0-2) & .53 & 266 & .67 & .68 & 53 \\
\hline & Medium (3-5) & .51 & 396 & .54 & $.55^{\mathrm{H}}$ & 103 \\
\hline & High (6-7) & $.68 \mathrm{ML}$ & 238 & .60 & $.72^{\mathrm{M}}$ & 68 \\
\hline & All & .56 & 900 & .59 & .63 & 224 \\
\hline \multirow[t]{4}{*}{ Attitude 3} & Low (0-2) & $.59 \mathrm{MH}$ & 266 & .73 & $.74 \mathrm{H}$ & 53 \\
\hline & Medium (3-5) & $.71 \mathrm{LH}$ & 396 & $.63 \mathrm{H}$ & $.81^{*}$ & 103 \\
\hline & High (6-7) & $.85 \mathrm{ML}$ & 238 & $.85^{M}$ & $.87 \mathrm{~L}$ & 68 \\
\hline & All & .75 & 900 & .75 & $.83 *$ & 224 \\
\hline \multirow[t]{4}{*}{ Attitude 4} & Low (0-2) & $.54 \mathrm{MH}$ & 266 & .73 & .84 & 53 \\
\hline & Medium (3-5) & $.68 \mathrm{LH}$ & 396 & $.65 \mathrm{H}$ & .73 & 103 \\
\hline & High (6-7) & $.78 \mathrm{ML}$ & 238 & $.75^{M}$ & .83 & 68 \\
\hline & All & .69 & 900 & .70 & $.79 *$ & 224 \\
\hline
\end{tabular}


Table 6 Cronbach's Alpha A cross Waves and Knowledge G roups N H S Poll

\begin{tabular}{|c|c|c|c|c|c|c|}
\hline Attitude & Knowledge & Full sample & & Weekend & Weekend & \\
\hline & Level & wave 1 & $\mathrm{n}$ & sample wave 1 & sample wave 2 & $\mathrm{n}$ \\
\hline \multirow[t]{4}{*}{ Attitude 1} & Low (0-2) & ".66H & 316 & $.72 \mathrm{H}$ & . $.55^{*}$ & 73 \\
\hline & Medium (3-5) & .54 & 288 & .53 & .50 & 68 \\
\hline & High (6-7) & $.50 \mathrm{~L}$ & 351 & $.49 L$ & .60 & 90 \\
\hline & All & .58 & 955 & .59 & .55 & 231 \\
\hline \multirow[t]{4}{*}{ Attitude2 } & Low (0-2) & .82 & 316 & $.84 \mathrm{H}$ & .80 & 73 \\
\hline & Medium (3-5) & .76 & 288 & .83 & $.73^{*}$ & 68 \\
\hline & High (6-7) & .79 & 351 & $.76^{\mathrm{L}}$ & .79 & 90 \\
\hline & All & .79 & 955 & .81 & .77 & 231 \\
\hline \multirow[t]{4}{*}{ Attitude 3} & Low (0-2) & $.61^{\mathrm{H}}$ & 316 & .52 & .65 & 73 \\
\hline & Medium (3-5) & .69 & 288 & .74 & .77 & 68 \\
\hline & High (6-7) & $.77^{\mathrm{L}}$ & 351 & .68 & .70 & 90 \\
\hline & All & .70 & 955 & .66 & .72 & 231 \\
\hline
\end{tabular}

Table 7 M eta-A nalysis of D ifference Between Baseline and Weekend Samples

$\begin{array}{lllll}\text { Weekend-Baseline Pooled Effect } & \text { 95\% confidence interval } & \text { Q } & \text { df } & \text { P }\end{array}$

$\begin{array}{llllll}0.014 & -0.002 & 0.029 & 23 & 15 & 0.098\end{array}$


Table 8 M eta-A nalysis of D ifferences Between Knowledge G roups

\begin{tabular}{lccc}
\hline \multicolumn{1}{c}{$\begin{array}{c}\text { Knowledge } \\
\text { Level }\end{array}$} & $\begin{array}{c}\text { Full sample } \\
\text { wave 1 }\end{array}$ & $\begin{array}{c}\text { Weekend } \\
\text { samplewave 1 }\end{array}$ & $\begin{array}{c}\text { Weekend } \\
\text { sample wave 2 }\end{array}$ \\
\hline \hline High-Low & $0.099^{*}$ & 0.024 & $0.038^{*}$ \\
Medium - Low & 0.031 & -0.009 & 0.009 \\
High - Medium & $0.067^{*}$ & 0.037 & $0.044^{*}$ \\
\hline \hline
\end{tabular}

Notes: First row shows pooled estimate of high knowledge group minus low knowledge group; second row the medium knowledge group minus low knowledge group and third row high knowledge group - medium knowledge group; * = significantly different from zero.

Table 9 M eta-A nalysis of Change Between waves one and two Weekend Sample

\begin{tabular}{lcccccc}
\hline $\begin{array}{c}\text { Knowledge } \\
\text { Level }\end{array}$ & $\begin{array}{c}\text { Change } \\
\text { Pooled Effect }\end{array}$ & \multicolumn{2}{c}{ 95\% Confidence Interval } & Q & df & P \\
\hline \hline Low (0-2) & 0.020 & -0.021 & 0.062 & 23 & 15 & 0.098 \\
Medium (3-5) & 0.022 & -0.012 & 0.055 & 21 & 15 & 0.129 \\
High (6-8) & 0.017 & 0.001 & 0.034 & 14 & 15 & 0.532 \\
All & $\mathbf{0 . 0 2 4}$ & $\mathbf{0 . 0 0 3}$ & $\mathbf{0 . 0 4 6}$ & $\mathbf{2 9}$ & $\mathbf{1 5}$ & $\mathbf{0 . 0 1 8}$ \\
\hline \hline
\end{tabular}




\section{APPENDIX 2 QUESTION WORDING FOR ATTITUDE SCALES}

\section{Election Issues Poll}

Attitude 1

1. "How much do you agree or disagree that people earning around $£ 50,000$ a year or more should pay higher income tax than now?" response scale $=5$ point Likert.

2. "Where do you stand on making people's incomes more equal? A reyou in the top box, agreeing completely with the statement alongside it (Government should try much harder to make incomes in Britain more equal)? Or in the bottom box, agreeing completely with that statement (Government should do nothing to make incomes in Britain more equal)? Or in one of the other boxes somewhere in between ? response scale $=7$ point Likert.

3. "Where do you stand on taxes and spending? A re you in the top box, agreeing completely with the statement al ongside it (Government should spend a lot more on services like education, health, even if it means putting up taxes a lot)? Or in the bottom box, agreeing completely with that statement (Government should spend much less on services like education and health in order to cut taxes)? Or in one of the other boxes somewhere in between? response scale $=7$ point Likert.

4. "Where do you stand on the minimum wage? A reyou in the top box, agreeing completely with the statement alongside it (Government should definitely introduce a minimum wage so that no employer can pay their workers too little)? Or in the bottom box, agreeing completely with that statement (Government should definitely not introduce a minimum wage because too many low paid workers would then lose their jobs)? Or in one of the other boxes somewhere in between? response scale $=7$ point Likert.

\section{M onarchy Poll}

Attitude 1 (all answered on 5-point Strongly Agree to Strongly disagree response scales)

1. People like me have no say in what the government does

2. I have opinions about politics that are worth listening to

3. In Britain today, it is too difficult for ordinary people to make their voices heard

4. I think I am better informed than most people about politics and government

Attitude 2 (all answered on 4-point Very important to $\mathrm{N}$ ot at all important response scales)

Here are some good things that the British monarchy is said to do. Please show how important you think the monarchy's role is in each of these areas.

1. Attracting tourists to Britain

2. Gaining international respect for Britain

3. Preventing any government abusing its power

4. Attracting trade to Britain

5. Linking Britain's present with its past

6. Uniting people throughout Britain

7. Keeping Britain a stable democracy

8. Publicising and helping 'good causes'

Attitude 3 (all answered on 5-point Strongly Agree to Strongly disagree response scales)

1. The monarchy is an expensive luxury that Britain cannot any longer afford

2. The monarchy comes across as too English, rather than representing Britain

3. The royal family benefits the rich and powerful at the expense of the rest of society

4. The monarchy props up a snobbish system of giving titles to people in high places

5. Having a monarchy stops Britain from adapting to the modern world

6. The monarchy keeps alive divisions between different classes in Britain

7. The monarchy makes Britain seem a stuck-up and stuffy country 
Attitude 4 (all answered on 5-point Strongly A gree to Strongly disagree response scales)

1. The British monarchy would be more acceptable if it did not depend on the taxpayer for so much support

2. If a Head of State is only a figurehead it doesn't matter whether they are elected or born into the job

3. A good thing about monarchs is that they are more likely to stand above politics than are elected Heads of State

4. It would be a good thing if the Queen had more powers

5. An elected Head of State would behave too much like any ordinary politician

6. Combining a monarch and a prime mi nister into a single H ead of State would give a single person too much political power

7. A good thing about monarchs over elected Heads of State is that they usually stay in office longer

\section{Europe Poll}

Attitude 1 (all answered on 5-point Strongly Agree to Strongly disagree response scales)

1. Unless Britain keeps its own currency, it will lose control of its own economic policy

2. The EU countries should be more than just a trading bloc - their governments should make joint decisions on other things too

3. Britain does not get enough out of the EU, in comparison to what it puts in

4. All things considered, Britain is a lot better off in the EU than out of it

5. Lots of good British traditions will have to be given up if we strengthen ties with the EU

6. The cost of living in Britain would rise significantly if we left the EU

7. Peace is much more secure because Britain is a member of the EU

8. Only the Germans have anything to gain from a single European currency

Attitude 2 (all answered on 5-point Strongly Agree to Strongly disagree response scales)

1. If we left theEU, Britain would lose its best chance of real progress

2. In a united Europe the various nations will lose their culture and their individuality

3. Competition from other countries in the EU is making Britain more modern and efficient

4. If we stay in the EU, Britain will lose too much control over decisions that affect Britain

5. There would be serious unemployment in Britain if weleft the EU

Attitude 3 (all answered on 5-point Strongly Agree to Strongly disagree response scales)

1. British seas should only be open to British fishing boats

2. Britain should sign up to the EU rules for protecting people's rights at work (the Social Chapter)

3. TheEU should expand its membership to include some of the ex-Communist countries of Eastern Europe

4. TheEU has too many petty rules and regulations which affect they way welive

5. If we signed up to the EU rules for protecting people's rights at work (the Social Chapter) would cost Britain jobs

Attitude 4 (all answered on 5-point Strongly A gree to Strongly disagree response scales) Taxpayers all over Europe are paying too much towards the costs of running the European Union

1. Only businessmen are benefiting from Britain being a member of the EU

2. If wehad a single European currency, British mortgage rates would be more likely to rise

3. EU rules are fairer to British farmers in most other European countries

4. Passport controls within the EU should be removed altogether

\section{NHS Poll}

Attitude 1 (all answered on 4-point Very likely to $\mathrm{N}$ ot at all likely response scales)

Suppose you had to go into your local NHS hospital for observation and maybe an operation. From what you know or have heard, please say how likely you think it would be that 
1. the hospital doctors would take seriously any complaints you make?

2. you would not be allowed home before you were really well enough to leave?

3. the hospital doctors would take seriously any views you had on the sorts of treatment available?

4. the operation would take place on the day it was booked to take place?

Attitude 2 (all answered on 5-point Strongly in favour to Strongly against response scales) One way of getting more money into the NHS is to charge people for certain things. How much would you bein favour of or against introducing charges for ...

1. visiting your GP?

2. your GP visiting you at home?

3. the cost of your hospital meals when you are an inpatient?

4. the cost of accommodation while you are in hospital?

5. using a non-emergency ambulance?

Attitude 3 (all answered on 5-point Strongly Agree to Strongly disagree response scales)

1. Most people who are very poor have only themselves to blame

2. We are too concerned nowadays about those who will never succeed in life

3. Life is never fair, and there is no point in government trying to make it fairer

\section{Crime Poll}

Attitude 1 (all answered on 5-point Strongly Agree to Strongly disagree response scales)

Here are some ideas for changing the legal system, and sentencing for criminals. Please tick one box for each idea to show how much you agree or disagree with it.

1. Fewer suspects should have the right to a jury trial.

2. A confession made during police questioning should not on its own be enough to convict someone.

3. The rules in court should be less on the side of the accused.

4. The courts should no longer treat suspects as innocent until proved guilty.

5. Suspects should have the right to remain silent under police questioning.

6. If a suspect remains silent under police questioning, this should count against them in court.

7. On-duty police officers should normally carry guns.

8. Complaints against the police should be investigated by an independent body, not the police themselves.

9. The police should sometimes be able to "bend the rules" to get a conviction.

Attitude 2 (all answered on 5-point Strongly Agree to Strongly disagree response scales)

1. And now, here are some ideas about sending people to prison. How much do you agree or disagree with each one?

2. The courts should send fewer people to prison.

3. Prison life should be made tougher and more unpleasant.

4. Only hardened criminals, or those who are a danger to society, should be sent to prison.

5. All murderers should be given a life sentence.

6. Courts should give tougher sentences to criminals.

7. Life sentences should mean life.

8. Prisons should try harder to reform prisoners, rather than just punishing them.

\section{Attitude3}

1. From what you know, or have heard, do you think that prison life in Britain is... (5-point scale much too tough to much too soft).

And how much do you agree or disagree that: 
2. Sending people to prison makes them more, not less, likely to become hardened criminals? And how much do you agree or disagree that more offenders should be...

3. Kept out of prison, but made to report regularly to probation officers.

4. Kept out of prison, but made to spend a certain amount of days hel ping people in the community.

5. Kept out of prison, but made to do military service for a period of time.

6. Kept out of prison but made to get training and counselling.

Attitude 4 (all answered on 5-point Very Effective to $\mathrm{N}$ ot at all Effective response scales)

Here are some ideas for hel ping to prevent crime in Britain. Please tick one box for each idea to show how effectiveyou think it is as a way of cutting crime.

1. Reduce unemployment.

2. Less violence and crime on television.

3. People making their property more secure.

4. Parents spending more time with their children.

5. More schemes like N eighbourhood Watch.

6. Teach children the differences between right and wrong.

7. Send more offenders to prison.

8. Firmer disciplinein schools.

9. Stiffer sentences generally.

10. More police on the beat. 


\section{A ppendix 3 Question Wordings and Codings for Knowledge Scales}

\section{Election Issues Poll}

This knowledge measure combined three true/ false items with four issue space items in the following manner:

ThreeI tem Knowledge Q uiz (A II true/false)

1. Prices have been rising by less than $5 \%$ a year over the past few years (true).

2. Interest rates are decided by the Bank of England (false).

3. Unemployment in Britain is higher than in Germany (false).

\section{Four Issue Space items}

All questions are answered on a 7 point scale and each item is repeated for each of the three main parties. For the knowledge measure, each item is scored one if respondent places the Conservative party to the right of the Labour party and the Liberal Democrats, zero otherwise.

1. Where do the Conservative party stand on making people's incomes more equal? A re they in the top box agreeing completely with the statement below? Or in the bottom box disagreeing completely with the statement? Or one of the boxes somewhere in between?

Government should try much harder to make incomes in Britain more equal.

2. Where do the Conservative party stand on taxes and spending? A re they in the top box agreeing completely with the statement below? Or in the bottom box disagreeing completely with the statement? Or one of the boxes somewhere in between?

Government should spend a lot more on services like education and health, even if it means putting up taxes a lot.

3. Where do the Conservative party stand on the minimum wage? A rethey in the top box agreeing completely with the statement bel ow? Or in the bottom box disagreeing completely with the statement? Or one of the boxes somewhere in between?

Government should definitely introduce a minimum wage so that no employer can pay their workers too little.

4. Where do the Conservative party stand on the European Union? A re they in the top box agreeing completely with the statement below? Or in the bottom box disagreeing completely with the statement? Or one of the boxes somewhere in between?

Government should do much more to unite fully with Europe.

Knowledge variable produced by summing all correct answers, giving a range 0-7. Knowledge groups were created on the following breaks: Low knowledge 0-? Correct; medium knowledge?-? correct; high knowledge?-? correct. Cronbach's Alpha for the scale was 0.68 .

\section{N H S Poll (all true/false)}

1. The standard charge for an NHS prescription is $f 10$.

2. The proportion of old people in Britain is getting larger and larger.

3. Even with inflation taken into account, government spending on the N HS has doubled over the last twenty years or so.

4. Most people nowadays get private medical treatment instead of using the NHS.

5. All British women can get free breast cancer screening on the NHS.

6. Cosmetic surgery is never available on the NHS.

Knowledge variable produced by summing all correct answers, giving a range $0-6$. Knowledge groups were created on the following breaks: Low knowledge 0-3 Correct; medium knowledge 4 correct; high knowledge 5-6 correct. Cronbach's Alpha for the scal e was 0.47. 


\section{Crime Poll (all true/false)}

1. British courts are allowed to sentence a murder to death.

2. Britain has a larger prison population than any other country in Western Europe.

3. Britain has more people serving life sentences than the rest of the European Community put together.

4. It is possible to be tried by a jury in a local magistrate's court.

5. The number of members of parliament is about 100.

6. The longest time allowed between general elections is four years.

7. Britain's electoral system is based on proportional representation.

8. No-one is allowed to be on the electoral register in two different places.

Knowledge variable produced by summing all correct answers, giving a range $0-8$. Knowledge groups were created on the following breaks: Low knowledge 0-2 Correct; medium knowledge 3-5 correct; high knowledge 6-8 correct. Cronbach's Al pha for thescal e was 0.56.

\section{Monarchy Poll (all true/false)}

1. After Prince Charles, Princess A nne is the next in line to the throne.

2. The Prime Minister, and not the Queen, is Britain's Head of State.

3. The Queen is still the head of the Commonwealth.

4. It is the Queen's duty to decide the date of all General Elections.

5. No prime minister takes office without being asked to by the Queen.

6. The Queen is the head of the Church of England.

7. The Queen is the head of the Church of Scotland.

8. Britain has an unwritten constitution.

Knowledge variable produced by summing all correct answers, giving a range $0-8$. Knowledge groups were created on the following breaks: Low knowledge 0-5 Correct; medium knowledge 6 correct; high knowledge 7-8 correct. Cronbach's Alpha for the scal e was 0.52 .

\section{Europe Poll (all true/false)}

1. The European Union has recently expanded to 15 members.

2. Switzerland is to join the European Union.

3. Britain's income tax rates are decided in Brussels.

4. Elections to the European Parliament are held every 5 years.

5. Of the three major British parties, the Liberal Democrats are the least in favour of the European Union.

Knowledge variable produced by summing all correct answers, giving a range $0-5$. Knowledge groups were created on the following breaks: Low knowledge 0-1 Correct; medium knowledge 2-3 correct; high knowledge 4-5 correct. Cronbach's A Ipha for the scale was 0.62 . 